Bangladesh J. Bot. 49(3): 541-547, 2020 (September)

\title{
COMPARISON OF SOIL ACTIVE ORGANIC CARBON FRACTIONS IN DIFFERENT VEGETATION ZONES IN PURPLE-SOIL OF HILL SLOPE
}

\author{
MANYUan Y ANG AND Ning Y ANG* $^{*}$ \\ College of Landscape Architecture, Hunan Environmental-Biological \\ Polytechnic College, Hengyang 421005, China
}

Keywords: Soil organic carbon, Grassland zone, Grassland-forest zone, Forest zone, Purple soil

\begin{abstract}
To explore the effect of vegetation restoration on soil carbon cycle and fractions of soil organic carbon pool on purple-soil hill slope in Hengyang City of Hunan Province, China was selected. The soil samples of 0 - 10 and $10-20 \mathrm{~cm}$ soil layers under three types of vegetation, i.e., grassland zone (GZ), grassland-forest zone (GFZ) and forest zone (FZ). The dynamics of soil active organic carbon (SAOC) fractions to provide theory basis for the influence of soil carbon cycle and different vegetation zones on the fractions of organic carbon pool and its stability. Results show: Microbial biomass carbon and easily oxidizable organic carbon exhibited a decreasing pattern: FZ, GZ, GFZ ( $\mathrm{p}<0.05)$; Dissolved organic carbon exhibited a decreasing pattern: FZ, GFZ, GZ ( $p<0.05)$; Light fraction organic carbon was the highest in FZ $(\mathrm{p}<0.05)$, and the second in GZ and GFZ; The availability of active organic carbon in $0-10 \mathrm{~cm}$ soil layer was higher than that of $10-20 \mathrm{~cm}$ soil layer ( $\mathrm{p}$-0.05); In comparison with GFZ, the herb in GZ could increase the contents of active organic carbon.
\end{abstract}

\section{Introduction}

Soil active organic carbon (SAOC), the active part of soil organic carbon (SOC), is considered as the organic carbon of high availability which is easy to be decomposed and mineralized by microorganism and directly supply nutrients to plants (Vieira et al. 2007). Some workers believe that the content of SOC is the result of the balance between the accumulation of organic carbon and its mineralization decomposition. Thus it cannot appropriately reflect the change in soil quality (Dodla et al. 2012). Although SAOC accounts for only a small part of the total SOC, it plays an important role in maintaining land productivity and reflecting the soil carbon storage variation, and is more sensitive to the micro-environment change of various vegetation than SOC. SAOC directly takes part in the process of soil biochemical conversion, and also acts as the energy for soil microbial activities and the driving force of soil nutrients (Wander et al. 1994). It reflects better availability of SOC and the soil quality (Boone et al. 1998, Wang et al. 2005). So, the investigation of SAOC is an important element for the research of dynamics and regulation mechanism of vegetation-soil carbon pool.

Purple-soil hilly slope land, covering an area of $1.625 \times 10^{5} \mathrm{hm}^{2}$, is one of the poorest areas in ecological environment in Hengyang city of Hunan Province, and also a typical area frequently hit by ecological disasters. The purple soil, with a short period of development, is extremely vulnerable to water erosion and infertile. Together with its strong heat absorptivity for its dark color, intensive evaporation for the heat on ground in summer, regional unbalanced allocation of water and heat resources and irrational development, the region has been faced with problems like sparse vegetation, severe water and soil erosion and seasonal draughts for a long time. The deteriorated ecological environment has seriously curbed the local rural economic development.

*Author for correspondence: <yangning8787@ sina.com>. 
At present, the studies of SAOC mostly focused on land use type (Fontaine et al. 2007, Paul et al. 2001), fertilization (Zhang et al.2007, Zhang et al. 2013), and the effect of specific region on SAOC (Whitbread et al. 1998, Bauhus et al. 1998). There are a few studies on the effect of different vegetation zones on the distribution of SAOC fractions. This study selected three vegetation types on the purple-soil hilly slope land in Hengyang city to investigate SAOC and its fractions. The results will be helpful to further understanding the effect of different vegetation zones on SOC accumulation, leaching and loss. Also, a basis is provided for the studies on SAOC, soil carbon cycle and the effect of vegetation restoration on the organic carbon pool's fractions and stability in purple-soil hilly slope land in Hengyang city.

\section{Materials and Methods}

The purple-soil hilly slope land is located in the south central Hunan, which is located in the middle reaches of Xiangiiang (geographical coordinate: $110^{\circ} 32^{\prime} 16^{\prime \prime}-113^{0} 16^{\prime} 32^{\prime \prime}$ E, $26^{0} 07^{\prime} 05^{\prime \prime}$ $\left.27^{0} 28^{\prime} 24^{\prime \prime} \mathrm{N}\right)$. Hengyang have the hillock as the main geomorphological type which is distributed in the middle of $60-200 \mathrm{~m}$ above sea level. This region has a subtropical monsoon humid climate, with an annual average temperature of $18^{\circ} \mathrm{C}$, extreme maximum temperature of $40.5^{\circ} \mathrm{C}$, extreme minimum temperature of $-7.9^{\circ} \mathrm{C}$, average annual rainfall of $1325 \mathrm{~mm}$ and annual average evaporation of $1426.5 \mathrm{~mm}$. The average relative humidity is $80 \%$, and the annual frost free period is 286 days (Yang et al. 2013).

In the middle of September 2017, three different vegetation types, i.e., grassland zone (GZ), grassland-forest zone (GFZ) and forest zone (FZ), were selected as the study object and the sample plots with an area greater than $1 \mathrm{hm}^{2}$ each were set in each vegetation zone (the vegetation zones were abandoned land initially) (Table 1). In each sample plot, three $20 \mathrm{~m} \times 20 \mathrm{~m}$ quadrats were set with an interval greater than $20 \mathrm{~m}$. In each quadrat, five sample points were taken in the shape of 'S'; soil samples at the depth of 0 - 10 and $10-20 \mathrm{~cm}$ soil layers were collected with a soil drill and those in the same layer were mixed. The soil samples were sealed in plastic bags and taken back to the lab. The visible plant debris and soil animals were removed carefully. Some of the soil samples were dried and some were stored at $-20^{\circ} \mathrm{C}$.

Table 1. The basic condition of different vegetation types.

\begin{tabular}{|c|c|c|c|c|}
\hline Vegetation types & GPS position & Slope $/\left({ }^{\circ}\right) /$ Aspect & Altitude/(m) & Dominant plants \\
\hline $\begin{array}{l}\text { Grassland zone } \\
\text { (GZ) }\end{array}$ & $\begin{array}{l}111^{0} 44^{\prime} 20^{\prime \prime} \mathrm{E} \\
26^{0} 46^{\prime} 35^{\prime \prime} \mathrm{N}\end{array}$ & $25 / \mathrm{SW}$ & 120 & $\begin{array}{l}\text { Setaria viridis }(S V) ; \text { Cynodon } \\
\text { dactylon }(C D)\end{array}$ \\
\hline $\begin{array}{l}\text { Grassland-forest } \\
\text { zone (GFZ) }\end{array}$ & $\begin{array}{l}110^{0} 30^{\prime} 56^{\prime \prime} \mathrm{E} \\
27^{0} 15^{\prime} 27^{\prime \prime} \mathrm{N}\end{array}$ & $30 / \mathrm{SW}$ & 125 & $\begin{array}{l}S V ; \text { Lagerstroemia indica }(L I) \\
\text { Abelia chinensis }(A C) ; \text { Serissa } \\
\text { japonica }(S J)\end{array}$ \\
\hline Forest zone (FZ) & $\begin{array}{l}112^{0} 37^{\prime} 56^{\prime \prime} \mathrm{E} \\
26^{0} 55^{\prime} 36^{\prime \prime} \mathrm{N}\end{array}$ & $25 / \mathrm{SW}$ & 120 & Liquidamdar formosana $(L F) ; L I$ \\
\hline
\end{tabular}

Soil $\mathrm{pH}$ was determined with electrode potential method; soil bulk density (SBD) was determined with cutting ring method; total nitrogen $(\mathrm{TN})$ was determined with semi-micro Kjeldahl method; total phosphorus (TP) was determined with $\mathrm{NaOH}$ melting/Mo-Sb colorimetry/UV spectrophotometry; total potassium (TK) was determined with $\mathrm{NaOH}$ meltingflame photometry; SOC was determined with potassium dichromate oxidation-heating method (Bao 2000); microbial biomass carbon (MBC) was determined through chloroform fumigation$\mathrm{K}_{2} \mathrm{SO}_{4}$ extraction and the carbon concentration of the extraction was determined with Shimadzu 
TOC-VCPH analyzer (conversion coefficient $K$ was 0.45 ) (Vance et al. 1987); easily oxidizable organic carbon (EOC) was determined with potassium permanganate $(333 \mathrm{mmol} / \mathrm{l})$ oxidation method (Wu et al. 2004); light fraction organic carbon (LFOC) was first separated by following methods of Janzen et al. (1992) method, and weighed after dried at $60^{\circ} \mathrm{C}$ for $24 \mathrm{hrs,} \mathrm{followed} \mathrm{by}$ the measurement through potassium dichromate heating method; dissolved organic carbon (DOC) was represented by the carbon content in the soil extract before fumigation.

SPSS13.0 software was used for data processing and statistical analysis. One-way ANOVA and least significant difference method (LSD) were adopted to compare the difference between different data. Pearson's correlation coefficient was used to analyze the correlation between SOC and SAOC. All data were the average value of three repeated measurements.

\section{Results and Discussion}

Table 2 shows that in the $0-10$ and $10-20 \mathrm{~cm}$ soil layers, the SBD in FZ was significantly lower than that of GZ and GFZ (p < 0.05). In $0-10 \mathrm{~cm}$ soil layer, the SBD in GZ and GFZ were 1.15 and 1.22 times than that of FZ, respectively; in $10-20 \mathrm{~cm}$ soil layer, they were 1.21 and 1.22 times than that of FZ. The difference between the SBD in $0-10$ and $10-20 \mathrm{~cm}$ soil layer of all vegetation types was not significant ( $p>0.05)$. In $0-10 \mathrm{~cm}$ soil layer, the TN content in GZ and GFZ was significantly lower than that in FZ ( $p<0.05$ ), being 24.77 and $26.15 \%$ of the latter, respectively. In $10-20 \mathrm{~cm}$ soil layer, the $\mathrm{TN}$ content in the three types of vegetation exhibited a decreasing pattern: FZ, GFZ, GZ ( $\mathrm{p}<0.05)$. For all the vegetation types, the TN content in $0-10$ $\mathrm{cm}$ soil layer was significantly higher than that in $10-20 \mathrm{~cm}$ soil layer $(\mathrm{p}<0.05)$. As for $0-10$ and $10-20 \mathrm{~cm}$ soil layers, the TP content in FZ was significantly higher than that in GZ and GFZ in the same soil layer $(\mathrm{p}<0.05)$. In $0-10 \mathrm{~cm}$ soil layer, the TP contents in GZ and GFZ were 80.00 and $80.00 \%$ of that in FZ, respectively; they were 86.76 and $85.29 \%$ of that in FZ in $10-20$ $\mathrm{cm}$ soil layer. The difference between the TP content in $0-10$ and $10-20 \mathrm{~cm}$ soil layers in GZ, GFZ and FZ was not significant ( $p>0.05)$. The TK content in different types of vegetation and different soil layers did not change significantly (change range $18.42-19.74 \mathrm{~g} / \mathrm{kg}$ ) $(\mathrm{p}>0.05)$.

Table 2 Soil basic physio-chemical properties under different vegetation types.

\begin{tabular}{lcccccc}
\hline $\begin{array}{l}\text { Vegetation } \\
\text { types }\end{array}$ & $\begin{array}{c}\text { Soil layer/ } \\
(\mathrm{cm})\end{array}$ & $\begin{array}{c}\text { Soil bulk } \\
\text { density/ } \\
\left(\mathrm{g} / \mathrm{cm}^{3}\right)\end{array}$ & $\begin{array}{c}\text { Total } \\
\text { nitrogen } \\
/(\mathrm{g} / \mathrm{kg})\end{array}$ & $\begin{array}{c}\text { Total } \\
\text { phosphorus/ } \\
(\mathrm{g} / \mathrm{kg})\end{array}$ & $\begin{array}{c}\text { Total } \\
\mathrm{kalium} / \\
(\mathrm{g} / \mathrm{kg})\end{array}$ & $\begin{array}{c}\text { Soil } \\
\mathrm{pH}\end{array}$ \\
\hline $\begin{array}{l}\text { Grassland zone } \\
(\mathrm{GZ})\end{array}$ & $0-10$ & $1.09 \mathrm{Aa}$ & $0.54 \mathrm{Aa}$ & $0.60 \mathrm{Aa}$ & $18.42 \mathrm{Aa}$ & $8.84 \mathrm{Aa}$ \\
Grassland-forest & $10-20$ & $1.21 \mathrm{Aa}$ & $0.39 \mathrm{Ab}$ & $0.59 \mathrm{Aa}$ & $18.86 \mathrm{Aa}$ & $8.90 \mathrm{Aa}$ \\
zone (GFZ) & $10-10$ & $1.16 \mathrm{Aa}$ & $0.57 \mathrm{Aa}$ & $0.60 \mathrm{Aa}$ & $19.26 \mathrm{Aa}$ & $8.94 \mathrm{Aa}$ \\
Forest zone (FZ) & $0-10$ & $1.22 \mathrm{Aa}$ & $0.45 \mathrm{Bb}$ & $0.58 \mathrm{Aa}$ & $19.65 \mathrm{Aa}$ & $8.95 \mathrm{Aa}$ \\
& $10-20$ & $1.00 \mathrm{Ba}$ & $1.24 \mathrm{Cb}$ & $0.68 \mathrm{Ba}$ & $19.70 \mathrm{Aa}$ & $8.63 \mathrm{Ba}$ \\
\hline
\end{tabular}

Different capital letters meant significant difference for the same soil layer and different vegetation types, and different small letters meant significant difference for the same vegetation types and different soil layers at 0.05 level. The same in below table.

The soil in different vegetation was all weak alkaline but the soil $\mathrm{pH}$ in $\mathrm{FZ}$ was significantly lower than that in GZ and GFZ ( $<$ 0.05). The soil pH in GZ and GFZ was 1.05 and 1.06 times than that of FZ of $0-10 \mathrm{~cm}$ soil layer and was 1.03 and 1.04 times that of FZ in $10-20 \mathrm{~cm}$ soil layer, 
respectively. The difference in the $\mathrm{pH}$ value of $0-10$ and $10-20 \mathrm{~cm}$ soil layers was not significant for all vegetation types $(\mathrm{p}>0.05)$.

Table 3 shows that the SOC content in different types of vegetation exhibited a decreasing pattern: FZ, GZ, GFZ (p < 0.05). In 0 - $10 \mathrm{~cm}$ soil layer, the contents of SOC in GZ and GFZ were just 69.25 and $30.90 \%$ of that in FZ; they were 79.65 and $51.36 \%$ than that of $10-20 \mathrm{~cm}$ soil layer. In GFZ, the difference of SOC content in $0-10$ and $10-20 \mathrm{~cm}$ soil layers was not significant ( $p>0.05)$. In GZ and FZ, the content of SOC of $0-10 \mathrm{~cm}$ soil layer was significantly higher than that in $10-20 \mathrm{~cm}$ soil layer $(\mathrm{p}<0.05)$; the content of $S O C$ in $0-10 \mathrm{~cm}$ soil layer was 1.47 and 1.69 times that of $10-20 \mathrm{~cm}$ soil layer.

Table 3. SOC content under different ecosystem (g/kg).

\begin{tabular}{lccc}
\hline \multirow{2}{*}{$\begin{array}{l}\text { Soil layer/ } \\
(\mathrm{cm})\end{array}$} & Grassland zone $(\mathrm{GZ})$ & Grassland-forest zone $(\mathrm{GFZ})$ & Forest zone $(\mathrm{FZ})$ \\
\cline { 2 - 4 } $0-10$ & $14.12 \mathrm{Aa}$ & $6.30 \mathrm{Ba}$ & $20.39 \mathrm{Ca}$ \\
$10-20$ & $9.63 \mathrm{Ab}$ & $6.21 \mathrm{Ba}$ & $12.09 \mathrm{Cb}$ \\
\hline
\end{tabular}

As shown in Table 4, the MBC content in $0-10$ and $10-20 \mathrm{~cm}$ soil layers in various vegetation exhibited a decreasing pattern: FZ, GFZ, GZ (p < 0.05). As for $0-10 \mathrm{~cm}$ soil layer, the MBC contents in GZ and GFZ were 69.49 and $76.31 \%$ of that in FZ; as for $10-20 \mathrm{~cm}$ soil layer, they were 73.93 and $81.07 \%$ of that in FZ, respectively. The difference in MBC content in $0-10$ and $10-20 \mathrm{~cm}$ soil layers was significant for all vegetation types $(\mathrm{p}<0.05)$. The $\mathrm{MBC}$ content in $0-10 \mathrm{~cm}$ soil layer in GZ, GFZ and FZ was $1.95,1.95$ and 2.08 times that of $10-20 \mathrm{~cm}$ soil layer.

The difference in the DOC content in different types of vegetation was significant $(p<0.05)$. In $0-10 \mathrm{~cm}$ soil layer, the content of DOC in FZ was 2.45 and 1.27 times that of GZ and GFZ, respectively; in $10-20 \mathrm{~cm}$ soil layer, it was 4.06 and 1.51 times than that of GZ and GFZ. The content of DOC in $0-10 \mathrm{~cm}$ soil layer was significantly higher than that in $10-20 \mathrm{~cm}$ soil layer in various vegetation $(\mathrm{p}<0.05)$. The content of DOC in $10-20 \mathrm{~cm}$ soil layer in GZ, GFZ and FZ was $127.40,67.42$ and $37.01 \%$ lower than that in $0-10 \mathrm{~cm}$ soil layer.

The content of LFOC in $0-10$ and $10-20 \mathrm{~cm}$ soil layers in FZ was significantly higher than those in the same soil layer in GZ and GFZ (p<0.05). In $0-10 \mathrm{~cm}$ soil layer, the contents of LFOC in GZ and GFZ were 57.92 and $56.88 \%$ of that in FZ, respectively; in $10-20 \mathrm{~cm}$ soil layer, they were 56.38 and $56.17 \%$ of that in FZ. As for GZ and FZ, the difference of LFOC content in 0 -10 and $10-20 \mathrm{~cm}$ soil layers were significant $(\mathrm{p}<0.05)$, the content of LFOC in $0-10 \mathrm{~cm}$ soil layer was 1.05 and 1.02 times than that of $10-20 \mathrm{~cm}$ soil layer, respectively. However, the difference between the LFOC content in $0-10$ and $10-20 \mathrm{~cm}$ soil layers was not significant for GFZ ( $p>0.05)$.

The content of EOC in $0-10$ and $10-20 \mathrm{~cm}$ soil layers in different vegetation exhibited a decreasing pattern: FZ, GZ, GFZ (p < 0.05). The content of EOC in $0-10 \mathrm{~cm}$ soil layer in GZ and GFZ was 39.50 and $25.57 \%$ of that in FZ; the proportion was 67.88 and $45.26 \%$ for $10-20 \mathrm{~cm}$ soil layer. In FZ, the content of EOC in $0-10 \mathrm{~cm}$ soil layer was 1.76 times that of $10-20 \mathrm{~cm}$ soil layer, indicating a significant difference ( $\mathrm{p}<0.05)$. As for GZ and GFZ, the difference between 0 10 and $10-20 \mathrm{~cm}$ soil layer was not significant $(\mathrm{p}>0.05)$.

The correlation coefficient $\left(r\right.$ ) between MBC and SOC was $0.642^{* *}$; the correlation coefficient $(r)$ between DOC and LFOC was $0.720^{* * *}$; the correlation coefficients $(r)$ between LFOC and SOC and between LFOC and MBC were $0.767^{* *}$ and $0.918^{* *}$, respectively; the correlation coefficients 
( $r$ ) of EOC with respect to SOC, MBC and LFOC were $0.900^{* *}, 0.658^{* *}$ and $0.688^{* *}$, respectively; the correlation coefficients $(r)$ of DOC with respect to SOC, MBC and EOC were $0.516^{*}, 0.522^{*}$ and $0.523^{*}$, respectively (note: ${ }^{*} \mathrm{p}<0.05,{ }^{* *} \mathrm{p}<0.01$ ). Thus, the contents of SAOC fractions were determined by the content of SOC to a large extent (Six et al. 2002).

Table 4 The properties of SAOC composition under different vegetation types.

\begin{tabular}{lcccc}
\hline SAOC & $\begin{array}{c}\text { Soil layer/ } \\
(\mathrm{cm})\end{array}$ & \multicolumn{3}{c}{ Vegetation types } \\
\cline { 3 - 5 } & & Grassland zone $(\mathrm{GZ})$ & $\begin{array}{c}\text { Grassland-forest zone } \\
(\mathrm{GFZ})\end{array}$ & Forest zone $(\mathrm{FZ})$ \\
\hline $\mathrm{MBC} /(\mathrm{mg} / \mathrm{kg})$ & $0-10$ & $257.43 \mathrm{Ca}$ & $282.67 \mathrm{Ba}$ & $370.43 \mathrm{Aa}$ \\
& $10-20$ & $131.87 \mathrm{Cb}$ & $144.61 \mathrm{Bb}$ & $178.38 \mathrm{Ab}$ \\
$\mathrm{DOC} /(\mathrm{mg} / \mathrm{kg})$ & $0-10$ & $72.45 \mathrm{Ca}$ & $139.90 \mathrm{Ba}$ & $177.39 \mathrm{Aa}$ \\
& $10-20$ & $31.86 \mathrm{Bb}$ & $83.56 \mathrm{ABb}$ & $129.47 \mathrm{Ab}$ \\
$\mathrm{LFOC} /(\mathrm{g} / \mathrm{kg})$ & $0-10$ & $2.78 \mathrm{Ba}$ & $2.73 \mathrm{Ba}$ & $4.80 \mathrm{Aa}$ \\
& $10-20$ & $2.65 \mathrm{Bb}$ & $2.64 \mathrm{Ba}$ & $2.70 \mathrm{Ab}$ \\
$\mathrm{EOC} /(\mathrm{g} / \mathrm{kg})$ & $0-10$ & $1.90 \mathrm{Ba}$ & $1.23 \mathrm{Ca}$ & $4.81 \mathrm{Aa}$ \\
& $10-20$ & $1.86 \mathrm{Ba}$ & $1.24 \mathrm{Ca}$ & $2.74 \mathrm{Ab}$ \\
\hline
\end{tabular}

The SOC content in the three types of vegetation exhibited a decreasing pattern: FZ, GZ, GFZ ( $\mathrm{p}<0.05$ ). This is basically similar with the results of Chaai et al. (2003). In FZ, due to good physical and chemical properties of the soil (Table 2) and a large amount of litter and root exudates, the content SOC is high; the content of SOC in GZ is higher than that in GFZ and the reason may be (i) the higher herbaceous plant cover in GZ, relatively stable ecological environment and microorganisms and higher assimilation input; (ii) as the ecological transition zone, GFZ has relatively high leaching and leaching loss and relatively high stress on microorganisms. Due to the joint effects of these two factors, the organic carbon in GZ is high than that in GFZ, but the specific reasons yet to be further explored; the rank of MBC in the three types of vegetation is similar with that of SOC. This indicates on one hand that MBC has a close relationship with SOC and on the other hand that a large amount of litter concentrates in $0-10 \mathrm{~cm}$ soil layer in FZ, so the water and ventilation condition is good, which is conducive to the growth and reproduction of microorganisms. Therefore, the MBC in FZ is the highest. Due to the higher herbaceous coverage and fine roots in GZ, the $\mathrm{MBC}$ in $\mathrm{GZ}$ is higher than that in MBC. Zou et al. (2005) reported that the higher vegetation cover in grassland slope and a larger amount of fine roots in the soil surface and suitable soil temperature and humidity were conducive to the accumulation of MBC; the leaching and leaching loss of soil erosion in the soil surface are the determinants of the difference in the content of EOC. Soil erosion intensity has an importance impact on the content of EOC (Degryze et al. 2004). The dense forest and canopy and deep litter layers in FZ have a good dissipation effect on rainfall and a blocking effect on runoff, so that the soil erosion in FZ is extremely low. Compared with GFZ, GZ has higher vegetation coverage and lower soil erosion; DOC is mainly composed of Humic acid, organic acids and carbohydrates with smaller molecules and 35 - 47\% of it exists in Humic acid (Carten 2002). From FZ to GZ, the litter and humus in soil organic matter decreases in turn, leading to a significant decrease in the content of DOC; LFOC is an organic matter between plant debris and humic organic matter and is composed of debris and root system of plants, which is mainly affected by plant root distribution, 
root exudates and microorganisms (Wang et al. 2005). In FZ, the good hydrothemal condition and rich types of organisms have an obvious effect on the decomposition of litter, so the LFOC in FZ is significantly higher than that in GZ and GFZ.

In $0-10 \mathrm{~cm}$ soil layer, the MBC content in FZ is the highest, followed by GZ and that in GFZ is the lowest. The MBC content in $0-10 \mathrm{~cm}$ soil layer of the three vegetation zones has a great difference $(113.00 \mathrm{mg} / \mathrm{kg}$ ), but the difference in $10-20 \mathrm{~cm}$ soil layer is small (just $46.51 \mathrm{mg} / \mathrm{kg}$ ) (Table 4). The microbial activities are frequent in $0-10 \mathrm{~cm}$ soil layer and the organic matter is easy to be decomposed, so the content of SAOC increases; the biologic effects in $10-20 \mathrm{~cm}$ soil layer is small, so the SAOC content is low (Shan et al. 2011). DOC is mainly sourced from the recent plant litter and humus in soil organic matter, including a series of organic matter from simple organic acid to complex macromolecular substances, such as humic acid and fulvic acid. That is why the content of DOC in $0-10 \mathrm{~cm}$ soil layer is higher than that in $10-20 \mathrm{~cm}$ soil layer. This is consistent with the result of Takata et al. (2008), i.e., DOC decreased with the increase in the depth of soil profile. Janzen et al. (1992) showed that the content of LFOC in $0-7.5 \mathrm{~cm}$ soil layer was $2-24 \mathrm{~g} / \mathrm{kg}$, which is basically consistent with the result of present study (2.64 -4.70 $\mathrm{g} / \mathrm{kg}$ in $0-10 \mathrm{~cm}$ soil layer) (Table 4). In different vegetation zones, the content of LFOC in $0-10$ $\mathrm{cm}$ soil layer changes significantly $(2.07 \mathrm{~g} / \mathrm{kg})$ while that in $10-20 \mathrm{~cm}$ soil layer changes very little $(0.06 \mathrm{~g} / \mathrm{kg}$ ) (Table 4). The difference of EOC content in $0-10$ and $10-20 \mathrm{~cm}$ soil layers in FZ is the highest $(2.07 \mathrm{~g} / \mathrm{kg})$, followed by that in GZ $(0.04 \mathrm{~g} / \mathrm{kg})$, and that in GFZ is the lowest $(0.01 \mathrm{~g} / \mathrm{kg}$ ) (Table 4), which is basically consistent with the result of Harris (2003). Chiorse et al. (1988) argued that at a certain soil depth, the microbial activities are limited by SAOC and the content of SAOC decreases from the upper to the lower soil layer. The deeper the soil layer, the lower the SOC availability will be.

\section{Acknowledgments}

This study was funded by the Project of Hunan Provincial Science \& Technology Department (S2006N332), and Scientific Research Project of the Education Department of Hunan Province (16C0559).

\section{References}

Bao S 2000. Agricultural and chemical analysis on soil (3rd Ed.). China Agriculture Press, Beijing.

Bauhus J, Pare DC and Cote L 1998. Effects of tree species stand age and soil type on soil microbial biomass and its activity in a southern boreal forest. Soil Biology \& Biochemistry 30(8): 1077-1089.

Boone RD, Nadelhoffer KJ and Canary JD 1998. Roots exert a strong influence on the temperature sensitivity of soil respiration. Nature 396(6711): 570-572.

Carten CT 2002. Soil carbon storage beneath recently established tree plantation in Tennessee and South Carolina, USA. Biomass and Bioenergy 23(2): 93-102.

Chaai A, Dexter M and Perron KW 2003. Hot-water extractable carbon in soils: A sensitive measurement for determining impacts of fertilization, grazing and cultivation. Soil Biology \& Biochemistry 35(9): 1231-1243.

Chiorse WC and Wilson JT 1988. Microbial ecology of terrestrial subsurface. Advances in Applied Microbiology 33: 107-172.

Degryze S, Six J and Paustian K 2004. Soil organic carbon pool changes following land-use conversions. Global Change Biology 10(7): 1120-1132.

Dodla SK, Wang JJ and Delaune RD 2012. Characterization of labile organic carbon in coastal wetland soils of the Mississippi River deltaic plain: Relationships to carbon functionalilies. Science of the Total Environment 10(1): 435-436. 
Fontaine S, Barot S and Barre P 2007. Stability of organic carbon in deep soil layers controlled by fresh carbon supply. Nature 450(7167): 277-280.

Harris JA 2003. Measurements of the soil microbial community for estimating the success of restoration. European Journal of Soil Science 54(4): 801-808.

Janzen HH, Campbell CA and Brandt SA 1992. Light-fraction organic matter in soils from long-term crop rotations. Soil Science Society of American Journal 56(6): 1799-1806.

Paul EA, Collins HP and Leavitt SW 2001. Dynamics of resistant soil carbon of Midwestern agricultural soils measured by naturally ${ }^{14} \mathrm{C}$ abundance. Geoderma 104(3-4): 239-256.

Shan YM, Chen DM and Guan XX 2011. Seasonally dependent impacts of grazing on soil nitrogen mineralization and linkages to ecosystem functioning in Inner Mongolia grassland. Soil Biology \& Biochemistry 43(9): 1943-1954.

Six J, Conant RT and Paul EA 2002. Stabilization mechanisms of soil organic matter: Implications for Csaturation of soils. Plant and Soils 241(2): 155-176.

Takata Y, Funakawa S and Yanai J 2008. Influence of crop rotation system on the spatial and temporal variation of the soil organic carbon budget in northern Kazakhstan. Soil Science and Plant Nutrition 54(1): 159-171.

Vance ED, Brookes PC and Jenkinson DC 1987. An extraction method for measuring soil microbial biomass C. Soil Biology \& Biochemistry 19(6): 703-707.

Vieira FC, Bayer BC and Zanatta JA 2007. Carbon management index based on physical fractionation of soil organic matter in an Acrisolunder long-term no-till cropping systems. Soil \& Tillage Research 96(6): 195-204.

Wander MM, Traina SJ and Stinner BR 1994. Organic and conventional management effects on biologically active and organic matter pools. Soil Science Society of America Journal 58(4): 1130-1139.

Wang QK, Wang SL and Deng SJ 2005. Comparative study on active soil organic matter in Chinese fir plantation and native broad-1eaved forest in subtropical China. Journal of Forestry Research 16(1): 23-26.

Wang W, Ohse $\mathrm{K}$ and Liu JJ 2005. Contribution of root respiration to soil respiration in a $\mathrm{C}_{3} / \mathrm{C}_{4}$ mixed grassland. Journal of Biosciences 30(4): 507-514.

Whitbread AM, Lefroy RDB and Blair GJ 1998. A survey of the impact of cropping on soil physical and chemical properties in north-western New South Wales. Australian Journal of Soil Research 36(4): 669681.

Wu JG, Zhang XQ and Yu DY 2004. Changes in Soil Labile Organic Carbon under Different Land Use in the Liupan Mountain Forest Zone. Acta Phytoecologica Sinica 28(5): 657-664.

Yang N, Zou DS, and Yang MY 2013. Relationships between Vegetation Characteristics and Soil Properties at Different Restoration Stages on Slope Land with Purple Soils in Hengyang of Hunan province, SouthCentral China. Chinese Journal of Applied Ecology 24(1): 90-96.

Zhang XY, Sui YY and Zhang XD 2007. Spatial variability of nutrient properties in black soil of Northeast China. Pedosphere 17(1): 19-29.

Zhang R, Zhang GL and Ji YY 2013. Effects of Different Fertilizer Application on Soil Active Organic Carbon. Environmental Science 34(1): 277-282.

Zou XM, Ruan HH and Fu Y 2005. Estimating soil labile organic carbon and potential turnover rates using a sequential fumigation in cubation procedure. Soil Biology \& Biochemistry 37(10): 1923-1928. 